\title{
Caracterização microestrutural e mecânica do aço maraging 300 soldado por processo a laser e a plasma e posteriormente envelhecido
}

\author{
Mechanical and microstructural characterization of maraging $\mathbf{3 0 0}$ steel \\ welded by laser and plasma process and subsequently aged
}

Cecília Vieira Gomes ${ }^{1}$, Miguel Justino Ribeiro Barboza'1, Deivid Ferreira da Silva², Sandro Lombardo³, Antônio Jorge Abdalla ${ }^{3,4}$

\section{RESUMO}

Aços maraging são ligas Ni-Co-Mo-Ti de ultra alta resistência de interesse no setor aeroespacial em razão de elevada resistência mecânica, aliada a uma excelente tenacidade. Tais propriedades mecânicas podem ser afetadas durante os processos de soldagem do aço em decorrência das altas temperaturas atingidas na região da solda e em suas proximidades. Sendo assim, o estudo da caracterização microestrutural e das propriedades mecânicas ao longo da região de soldagem têm importância tecnológica para o estudo e aprimoramento deste material. Dois processos de solda foram investigados, de forma comparativa, para analisar a viabilidade da soldagem do aço maraging 300, o processo a plasma (Plasma Arc Welding - PAW) e a laser (Laser Beam Welding - LBW). Após a realização da solda, corpos de prova de tração foram submetidos ao tratamento térmico de envelhecimento para elevar os níveis de resistência do material. A microestrutura do material base, da Zona Fundida (ZF) e Zona Termicamente Afetada (ZTA) foram analisadas por microscopia ótica e ensaios de dureza por microindentação. Ensaios de tração foram realizados para investigar as propriedades mecânicas. Estas propriedades foram correlacionadas com a microestrutura e o tipo de solda realizado.

Palavras-chave: Aço maraging; Tratamentos térmicos; Caracterização microestrutural; Propriedades mecânicas.

\begin{abstract}
Maraging steels are Ni-Co-Mo-Ti ultra high strength alloys of great interest in aerospace sector due to their mechanical strength combined with high toughness. These mechanical properties can be affected by high temperatures in some areas of the material while welding processes are made. Accordingly, the study of microstructural characterization and mechanical properties along the weld bead has a great technological importance for the improvement of this type of steel. Two welding processes were investigated in a comparative way, to analyze the feasibility maraging 300 steel welding: the plasma process (Plasma Arc Welding - PAW) and the laser process (Laser Beam Welding - LBW). After being welded by PAW and LBW processes, the specimens were subjected to aging heat treatment to increase the material strength levels. Then the microstructure of the base material, the Fused Zone (ZF) and Heat Affected Zone (HAZ) were analyzed by optical microscopy and microhardness tests. Tensile tests were carried out to investigate the mechanical properties. These properties are related to the microstructure and the type of weld performed.
\end{abstract}

Keywords: Maraging steel; Heat treatment; Microstructural characterization; Mechanical properties

\footnotetext{
'Universidade de São Paulo - Escola de Engenharia de Lorena - Lorena (SP) - Brasil

${ }^{2}$ Instituto de Aeronáutica e Espaço - Divisão da Garantia do Produto Espacial - São José dos Campos (SP) - Brasil

${ }^{3}$ Universidade Estadual Paulista Júlio de Mesquita Filho - Faculdade de Engenharia de Guaratinguetá - Guaratinguetá (SP) - Brasil

${ }^{4}$ Instituto de Estudos Avançados - Departamento de Fotônica - São José dos Campos (SP) - Brasil

Autor correspondente: Antonio Jorge Abdalla - IEAv - Dep. Fotônica - Trevo Coronel Aviador José Alberto Albano do Amarante, Putim, 01 -

CEP 12228-001 - São José dos Campos (SP) - Brasil

E-mail: abdalla@ieav.cta.br
}

Recebido: 26/10/2015 Aprovado: 22/02/2016 


\section{INTRODUÇÃO}

Aços maraging são ligas Ni-Co-Mo-Ti amplamente utilizadas no setor aeroespacial devido a sua combinação de alta resistência mecânica com alta tenacidade, boa estabilidade térmica e resistência a frio e estabilidade dimensional durante tratamentos térmicos ${ }^{(1,2,3)}$. Tais propriedades podem ser afetadas em decorrência das altas temperaturas atingidas durante os processos de soldagem neste material, de maneira que ocorra a diminuição da vida útil do aço e/ou redução de suas propriedades mecânicas, torna-se importante o controle da temperatura nos tratamentos térmicos aplicados ${ }^{(4,5)}$.

Neste trabalho, foram analisados os processos de soldagem a plasma e a laser no aço maraging, seguido de tratamento térmico de envelhecimento do material e comparação das principais características microestruturais e das propriedades mecânicas resultantes.

No processo de soldagem a plasma a fusão dos metais é provocada por um arco elétrico constritor envolto por uma atmosfera protetora de gás inerte (geralmente argônio), que fica localizado entre um eletrodo de tungstênio nãoconsumível e a peça ${ }^{(4)}$. O diâmetro do arco é restringido através de um bocal, desta maneira é possível regular a intensidade da fonte de calor.

A técnica soldagem a laser, por sua vez consiste na utilização de um feixe de radiação eletromagnética de frequência única, com relações de fase bem definidas e de alta intensidade que incide na superfície metálica ${ }^{(6,7)}$. Ao ser absorvida pela superfície, a temperatura na região se eleva provocando fusão localizada ${ }^{(7,8)}$.

Ambos os processos de soldagem introduzem características indesejadas na região afetada pelo calor, tais como crescimento de grãos, poros e formação de austenita retida que resultam em perda das propriedades mecânicas do aço ${ }^{(5-8)}$. Com a finalidade de melhoria das características microestruturais e das propriedades mecânicas, o tratamento térmico de envelhecimento a $480{ }^{\circ} \mathrm{C}$ durante o período de $3 \mathrm{~h}$ foi realizado nas amostras, que por sua vez tiveram suas propriedades analisadas e comparadas.

\section{MATERIAIS E MÉTODOS}

$\mathrm{O}$ aço maraging 300 foi produzido pela empresa BÖHLER, que utiliza a nomenclatura de V720, a análise química do material recebido está discriminada na Tabela 1. Os resultados mostram que a composição está de acordo com o esperado pela norma AMS 6521C ${ }^{(9)}$ para o aço maraging (18Ni) 300.

O material foi recebido em forma de chapas com 3,35 mm de espessura, estas foram cortadas com secção quadrada de $200 \mathrm{~mm}$, as extremidades foram lixadas e limpas com acetona e posteriormente submetidas aos processos de soldagem. Foram utilizados dois processos de soldagem, PAW (Plasma Arc Welding) e a LBW (Laser Beam Welding). Os principais parâmetros utilizados nestes processos estão descritos na Tabela 2.

Após o processo de soldagem, foram confeccionados os corpos de prova para ensaios de tração, de forma que a o cordão de solda ficasse localizado no centro do corpo de prova. Os corpos de prova foram usinados conforme norma ASTM E8/E8M ${ }^{(10)}$ no sentido longitudinal de laminação.

Antes da realização dos ensaios de tração os corpos de prova foram envelhecidos a $480{ }^{\circ} \mathrm{C}$ por 3 horas, estes parâmetros foram utilizados baseados em trabalhos anteriores ${ }^{(8,11)}$.

Os ensaios de tração foram realizados em uma máquina de ensaios universal servo-hidráulica tipo MTS, modelo $810.23 \mathrm{M}$, com $250 \mathrm{kN}$ de capacidade com a velocidade de ensaio de $1 \mathrm{~mm} / \mathrm{min}$.

Amostras de cada um dos tipos de solda foram retiradas antes e após o tratamento térmico de envelhecimento. As amostras foram embutimentas, lixadas com lixas d'água de granulometrias 250, 400, 600, 800 mesh e, em seguida, polidas com suspensão de OPU. Após o polimento as amostras foram atacadas com solução de Nital 5\%.

A caracterização microestrutural foi realizada com a utilização do microscópio óptico de luz polarizada Leica DM IRM. As imagens foram capturadas com câmera Samsung Digital Color SCC-131.

Table 1: Composição química do aço maraging 300 (\% em peso).

\begin{tabular}{c|c|c|c|c|c|c|c|c|c|c|c|}
\hline Elemento & Ni & Co & Mo & Ti & Al & C & S & P & So & Mn & Fe \\
\hline$\%$ p. & 19,00 & 9,37 & 4,94 & 0,63 & 0,08 & 0,008 & 0,002 & 0,004 & 0,06 & 0,01 & balanço \\
\hline
\end{tabular}

Tabela 2: Parâmetros utilizados nos processos de soldagem a Plasma e a Laser.

\begin{tabular}{|c|c|c|}
\hline & Solda a Plasma (PAW) & Solda a Laser (LBW) \\
\hline Corrente $(\mathrm{A})$ & 133 & - \\
\hline Velocidade de soldagem $(\mathrm{mm} / \mathrm{min})$ & 300 & 1800 \\
\hline Vel. de alimentação do arame de adição $(\mathrm{m} / \mathrm{min})$ & 1680 & - \\
\hline Fluxo do gás de proteção $(\mathrm{l} / \mathrm{min})$ & 25 & 30 \\
\hline Fluxo do gás de plasma $(\mathrm{l} / \mathrm{min})$ & 3,5 & - \\
\hline Fluxo do gás de purga $(\mathrm{l} / \mathrm{min})$ & 25 & - \\
\hline Potência do Laser $(\mathrm{W})$ & - & - \\
\hline Voltagem $(\mathrm{V})$ & 46 & 1800 \\
\hline
\end{tabular}


Os ensaios de microdureza foram realizados na escala Vickers através do microdurômetro SHIMADZU HMV-2TE com aplicação de carga de 1,961 N durante 5 segundos.

\section{RESULTADOS E DISCUSSÕES}

A micrografia da Fig. 1 mostra a região da Zona Fundida (ZF) da solda realizada pelo processo a plasma, antes do envelhecimento. A estrutura é dendrítica e celular e composta basicamente pela fase martensítica que, no aço maraging tem dureza reduzida, se comparada com a fase martensítica dos aços ao carbono tradicionais, conforme pode ser observado no gráfico da Fig. 2, em torno de $300 \mathrm{HV}$.

Ao analisar o gráfico de dureza da Fig. 2, pode-se notar que uma parte da Zona Termicamente Afetada, ZTA 1, mais próxima da $\mathrm{ZF}$, tem dureza em torno de $300 \mathrm{HV}$, indicando que nesta região a temperatura foi suficiente para ocorrer transformação de fases, formação de austenita no aquecimento e, ao resfriar, formação novamente de martensita. Na parte da ZTA, mais distante da ZF, nota-se uma elevação da dureza, para cerca de $500 \mathrm{HV}$, indicando que nesta região houve envelhecimento. Esta ocorrência evidencia que a faixa de temperatura deve ter atingindo cerca de 400 a

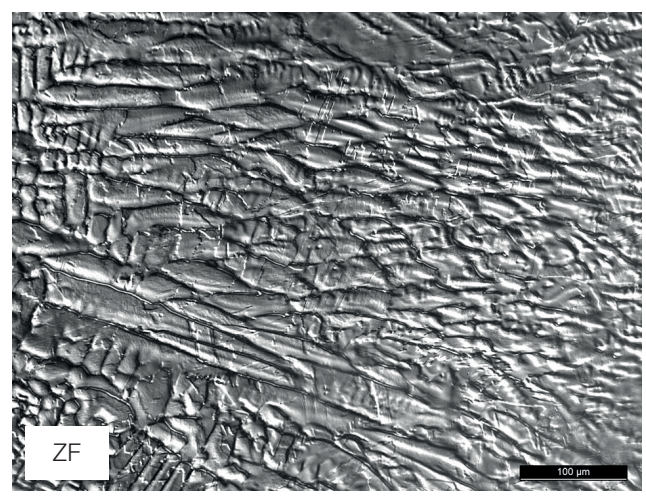

Figura 1: Microscopia Óptica: Microestrutura da Zona Fundida (ZF), aço maraging soldado a plasma, não envelhecido (ataque Nital $5 \%)$.

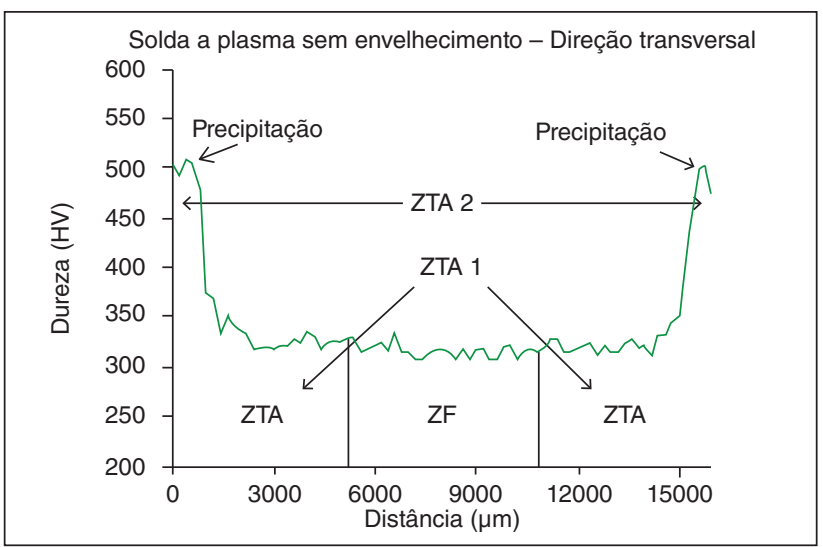

Figura 2: Dureza do aço maraging soldado a plasma não envelhecido. Mostrando a dureza na Zona Fundida (ZF) e Zona Termicamente Afetada (ZTA).
$600{ }^{\circ} \mathrm{C}$, temperaturas favoráveis à precipitação de intermetálicos. Vários autores observaram este fenômeno e chamam esta região de envelhecimento de ZTA $2^{(8,11,12)}$.

A micrografia da Fig. 3 corresponde à ZF da solda feita pelo processo a laser. Devido ao rápido aquecimento e resfriamento posterior, as estruturas são mais refinadas, porém tem morfologia semelhante às formadas pelo processo a plasma, nota-se a presença de dendritas alongadas na direção da extração de calor durante o resfriamento.

O gráfico da Fig. 4 mostra o perfil de dureza através da ZF, ZTA, até atingir o material base. Nota-se uma queda na dureza na ZF, esta redução decorre principalmente da presença de austenita e de defeitos provenientes do processo de soldagem, principalmente poros, resultados semelhantes foram relatados na literatura ${ }^{(9,11)}$

Ao se comparar o tamanho da ZF e ZTA formadas na soldagem a laser, com relação a estas mesmas regiões formadas pela soldagem a plasma, nota-se que são cerca de sete vezes menor, resultados semelhantes foi observado por Sakai et al. e Souza Neto et.al. ${ }^{(13,14)}$. Nota-se que, de forma semelhante à soldagem a plasma, há a formação de duas regiões distintas na ZTA, ZTA 1, próximo a ZF e ZTA 2, onde há envelhecimento e aumento na dureza. O valor na dureza da ZTA 2 (cerca de $350 \mathrm{HV}$ ) é inferior ao observado na esta mesma região para o processo de soldagem a

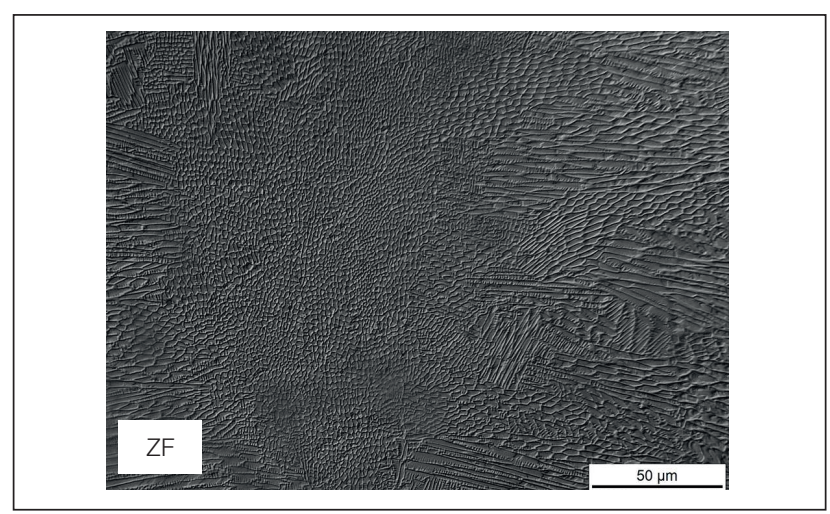

Figura 3: Microscopia Óptica: Microestrutura da Zona Fundida (ZF) do aço maraging soldado a laser não envelhecido (ataque - Nital 5\%).

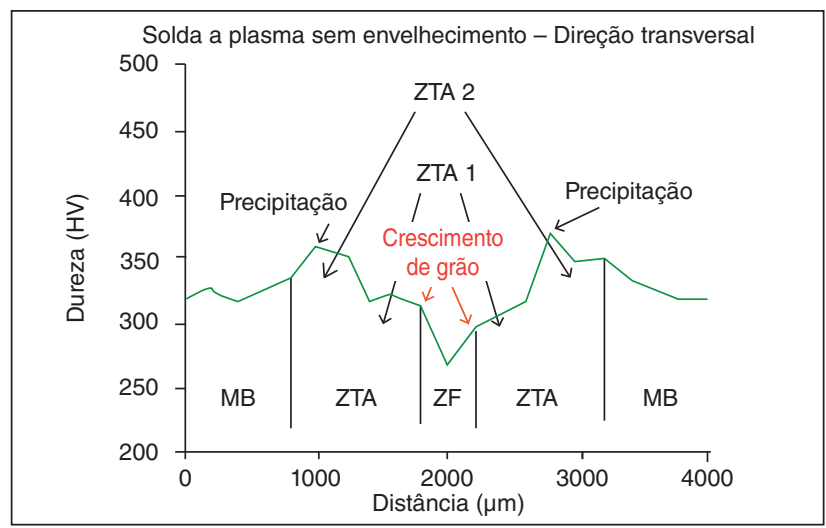

Figura 4: Dureza da amostra soldada pelo processo a laser sem envelhecimento, mostrando dureza na Zona. 
plasma (cerca de $500 \mathrm{HV}$ ), este fato está relacionado com o aporte térmico, a velocidade de soldagem do laser (6 vezes maior) e o fato de que o feixe de laser se restringe a uma área mais estreita. A redução na temperatura e o menor tempo de permanência desta temperatura na ZTA 2, no processo a laser, reduzem a formação de precipitados e, por conseguinte, a dureza na região.

As micrografias das Figs. 5 e 6 mostram respectivamente a estrutura da solda realizada pelos processos a plasma e a laser. A ZF da solda formada no processo a laser são reduzidas, em comparação com o processo a plasma. O mesmo fenômeno ocorre com a ZTA, que, no aço soldado a plasma, pode atingir até cerca de 10 vezes o tamanho da ZTA observada na solda a laser ${ }^{(14)}$. Nota-se ainda, na imagem da Fig. 6, a presença de poros, estes defeitos contribuem para reduzir os valores de dureza na ZF, conforme observado no gráfico de dureza da Fig. 4. Outros autores encontraram defeitos semelhantes ao utilizar a soldagem a laser, estes autores utilizaram, além do aço maraging, também outros tipos de aço como AISI 4340, 4130 e o aço $300 \mathrm{M}$, os poros foram encontrados na ZF de todos estes tipos de aços estudados ${ }^{(6,8,14)}$.

As amostras que passaram pelo tratamento térmico de envelhecimento apresentaram maior resistência mecânica em relação àquelas não envelhecidas. Isso ocorreu devido à formação

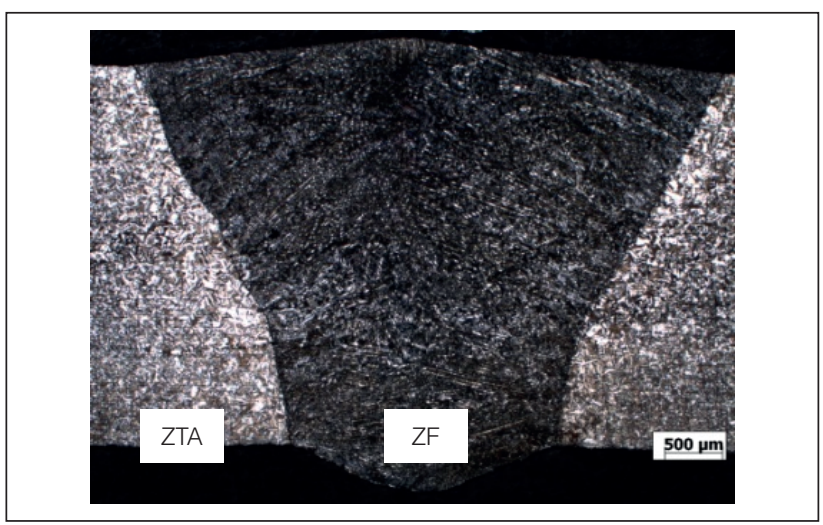

Figura 5: Microscopia Óptica: mostrando a ZF e ZTA do aço maraging soldado a plasma (ataque Nital $5 \%$ ).

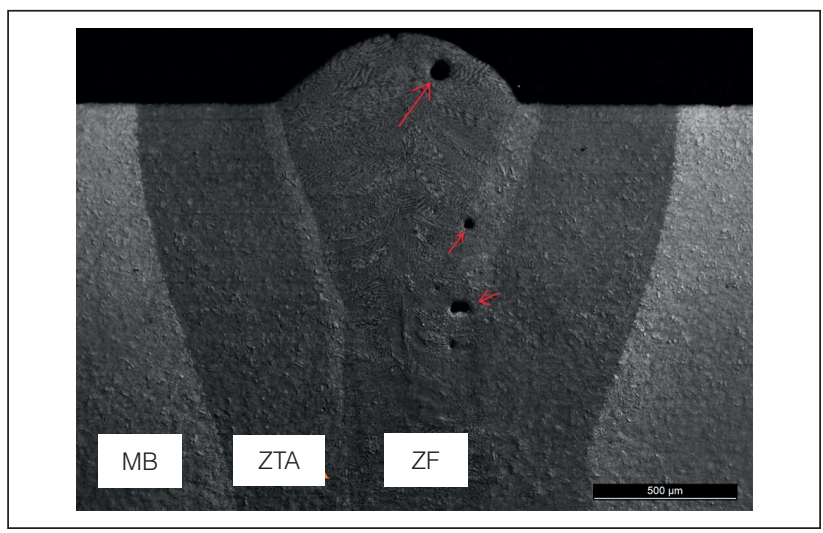

Figura 6: Microscopia Óptica: mostrando a ZF, ZTA e MB do aço soldado a laser. As Setas mostram defeitos de soldagem (poros) (ataque Nital 5\%). de precipitados intermetálicos na matriz martensítica durante o tratamento térmico. O aumento de dureza foi observado tanto no material base como na ZTA e na ZF. O ganho na dureza, após o tratamento térmico de envelhecimento, ocorreu tanto para o processo de soldagem a laser como para o processo a plasma. Os gráficos das Figs. 7 e 8 mostram esta ocorrência, nota-se que, principalmente na zona fundida, há uma redução nos valores da dureza. Esta diminuição foi associada, principalmente, à formação de austenita, esta fase foi encontrada após a soldagem e envelhecimento, tanto no aço soldado pelo processo a plasma como no aço soldado pelo processo a laser. No caso da solda a laser há o agravante da formação de pequenos poros, estes contribuem para a redução na dureza.

As micrografias das Figs. 9 e 10 mostram detalhes com maior aumento da ZF com a finalidade de destacar a presença da austenita (regiões brancas) entre as dendritas. Esta austenita, após o envelhecimento não contribui para a elevação da dureza. A matriz martensítica, com coloração cinza, é a principal responsável pela elevação nos níveis de dureza e de resistência do material. A martensita contém elevada densidade de discordâncias e, após o envelhecimento, há a formação de um grande número de precipitados que contribui para ancorar as discordâncias, dificultando assim a deformação plástica, este mecanismo exige uma elevação nos níveis de resistência para que a deformação plástica ocorra ${ }^{(1,2,8)}$.

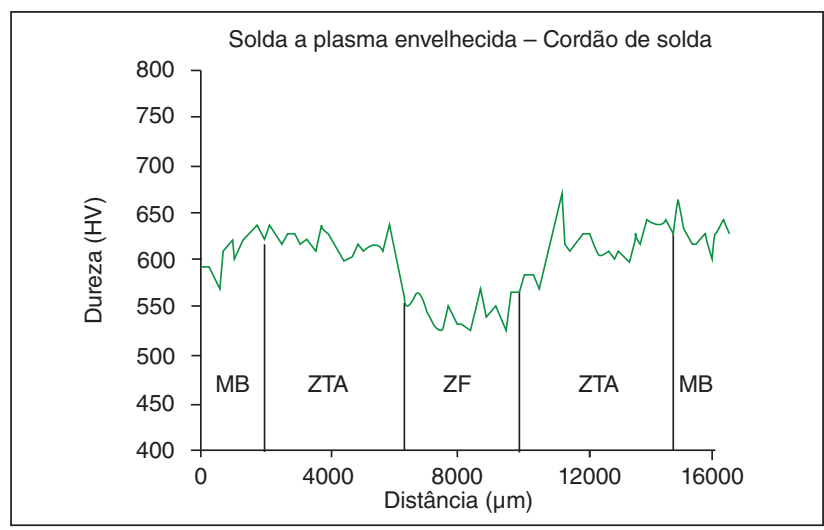

Figura 7: Dureza no material de base, ZF e ZTA, do aço maraging soldado pelo processo a plasma e posteriormente envelhecido.

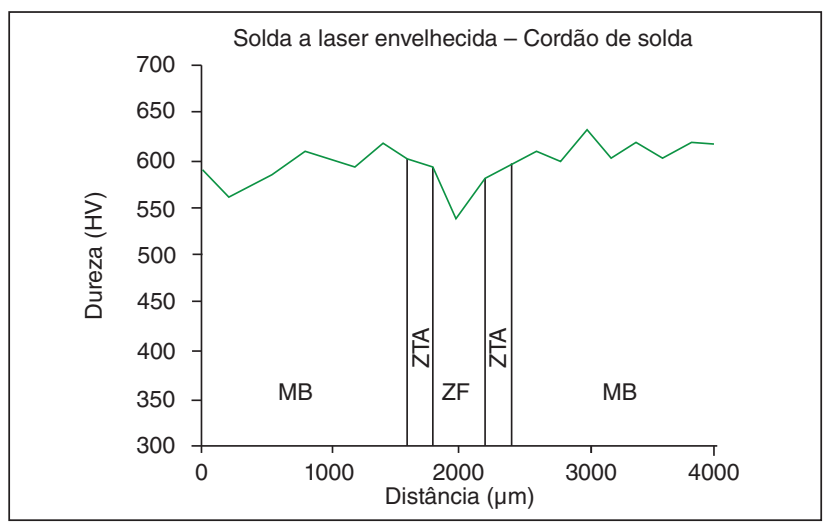

Figura 8: Dureza no material de base, ZF e ZTA, do aço maraging soldado pelo processo a laser e posteriormente envelhecimento. 
As Figs. 11 e 12 mostram a região de transição entre a ZF e a ZTA para o aço maraging soldado a laser e a plasma, respectivamente. Observa-se que, devido ao maior aporte térmico, há um crescimento de grão mais notório, nesta região, no aço soldado a plasma. Este fato é importante, pois o crescimento de grão irá reduzir a dureza e resistência neste local específico, tornando-o mais susceptível ao início de uma trinca ao ser solicitado mecanicamente.

Os testes de tração mostraram melhor desempenho mecânico para o aço maraging 300 soldado pelo processo a laser, atingindo valores médios de limite de resistência de $1875 \mathrm{MPa}$, conforme apresentados na Tabela 3 .

O limite de resistência do aço maraging 300 sem solda e envelhecido está de acordo com o catálogo do fabricante (entre 1860 a 2260 $\mathrm{MPa}$ ) e serve como referência para avaliar os processos de soldagem utilizados ${ }^{(15)}$. Observa-se que a perda no limite de resistência dos aços soldados, em comparação com o não soldado, foi pequena, cerca de $4 \%$ para o aço soldado a laser e cerca de $6 \%$ para o aço soldado a plasma, indicando que os dois processo de soldagem foram eficientes com relação à resistência mecânica em tração.

Uma das aplicações importantes a que se destina este aço, é a fabricação de envelopes motores de veículos lançadores de

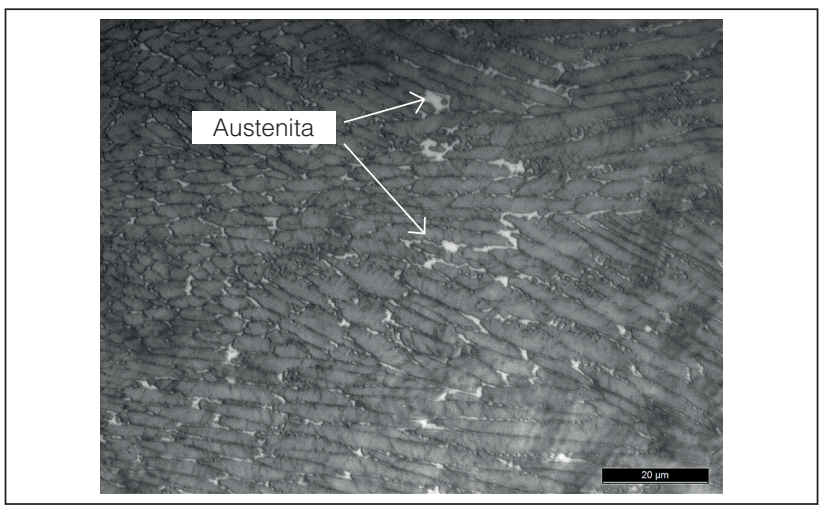

Figura 9: Microscopia Óptica: mostrando a presença de austenita (branca) entre as dendritas na ZF do aço maraging soldado a laser e envelhecido (ataque - Nital 5\%).

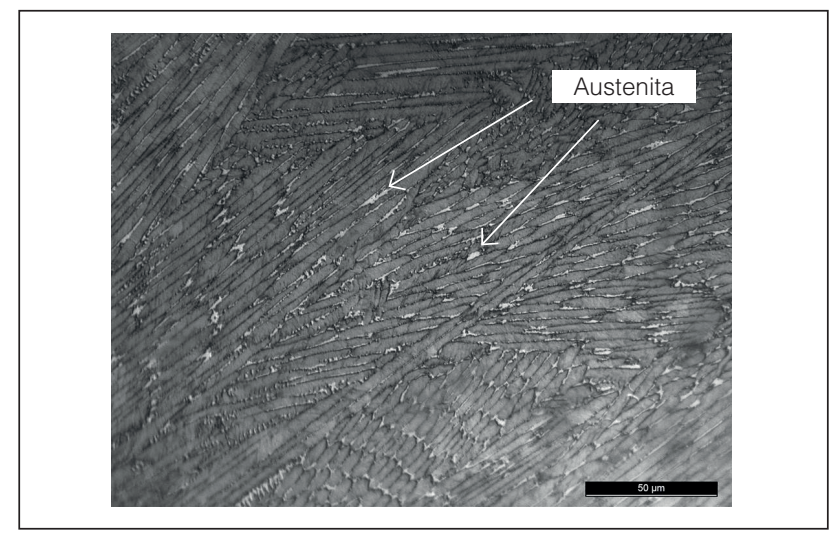

Figura 10: Microscopia Óptica: mostrando a presença de austenita (branca) entre as dendritas na ZF do aço maraging soldado a plasma e envelhecido (ataque - Nital 5\%). satélites, cujo projeto requer limites de resistência superiores a $1765 \mathrm{MPa}$, neste requisito, ambos processos de soldagem estariam aptos de serem utilizados ${ }^{(16)}$.

Tabela 3: Resultados dos testes de tração.

\begin{tabular}{c|c|}
\hline $\begin{array}{c}\text { Aço maraging } \mathbf{3 0 0} \\
\text { envelhecido }\end{array}$ & $\begin{array}{c}\text { Limite de Resistência } \\
\text { à Tração }(\mathbf{M P a})\end{array}$ \\
\hline Sem solda & $1950 \pm 28$ \\
LBW (laser) & $1875 \pm 47$ \\
\hline PAW (plasma) & $1829 \pm 34$ \\
\hline
\end{tabular}

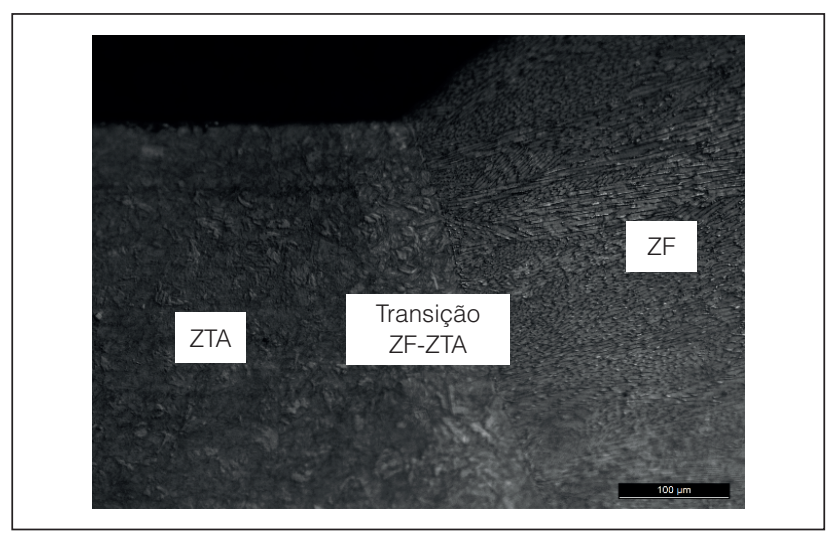

Figura 11: Microscopia Óptica: Região de transição entre a ZF e a ZTA. Processo a laser, mostrando pequeno crescimento de grãos (ataque - Nital 5\%).

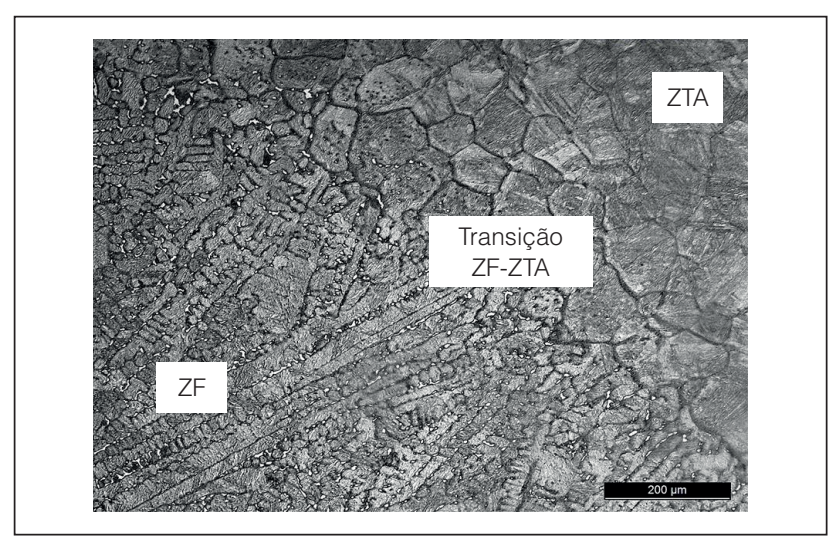

Figura 12: Microscopia Óptica: Região de transição entre a ZF e a ZTA. Processo a laser, região com notório crescimento de grãos (ataque - Nital 5\%).

\section{CONCLUSÕES}

O processo de tratamento térmico de envelhecimento é fundamental para elevar os níveis de dureza e de resistência do aço maraging 300, a manutenção do aço na temperatura de $480{ }^{\circ} \mathrm{C}$ durante 3 horas, mostrou-se eficiente para atingir este propósito.

Comparando-se os aços soldados pelos dois processos estudados com o aço maraging 300 sem solda, nota-se que a perda na resistência mecânica foi pequena. A redução no limite de resistência para o aço soldado a laser foi inferior a $4 \%$ e, no aço soldado a plasma, foi inferior a 7\%. Esta boa soldabilidade do aço 
maraging 300 o credencia para uma série de aplicações, inclusive na área aeroespacial, para fins estruturais.

A técnica de soldagem a laser mostrou algumas vantagens, pois, além da reduzida perda no limite de resistência, tem uma velocidade de soldagem maior que a realizada pelo processo a plasma.

\section{AGRADECIMENTOS}

Os autores agradecem à Fundação de Auxílio à Pesquisa do Estado de São Paulo - FAPESP pelo suporte financeiro (Processo $\left.n^{\circ} 2015 / 01318-0\right)$

\section{REFERÊNCIAS}

1. REIS, A. G.; REIS, D. A. P.; ABDALLA, A, J.; OTUBO, J., Avaliação das propriedades de Fluência a $600^{\circ} \mathrm{C}$ do Aço Maraging 300 Solubilizado. Tecnol. Metal. Mater. Miner., São Paulo, v. 11, n. 1, p. 22-26, jan./mar. 2014.

2. SILVA, A.L.C.S.; MEI. P.R., Aços e Ligas Especiais, third ed., Edgar Blucher, São Paulo, 2011, 664 p.

3. SHAMANTHA, C.R.; NARAYANAN, R.; IYER, K.J.L.; RADHAKRISHAN, V.M.; SESHADRI, S.K.; SUNDARARAJAN, S.; SUNDARESAN, S., Microstructural changes during welding and subsequent heat treatment of $18 \mathrm{Ni}$ (250-grade) maraging steel, Materials Science and Engineering, v. 287 (2000) 43-51.

4. BRACAREnCE, A, Q., Processo de Soldagem PAW, editado pelo autor Belo Horizonte, 2000.

5. SCHIMIDT, M.; ROHRBACK, K., ASM Handbook - Heat treating, In: Heat treating of Maraging Steels, ASM International, v.4, USA, 1991, pp. 528-548

6. CARDOSO, A. S. M, Caracterização mecânica e microestrutural dos aços SAE 4340 e 300M após soldagem a laser e tratamento superficial de nitretação a plasma. 2011, 15 p. Escola de Engenharia de Lorena.

7. KAVAMURA, H, K., Aplicação de Solda Laser em Carrocerias Automotivas: Estudo Comparativo Entre a Solda Laser e a
Solda Ponto por Resistência. 2007, 10 p. Escola Politécnica da Universidade de São Paulo, 2007

8. FANTON, L.; ABDALLA, A.J. ; LIMA, M.S.F., Heat Treatment and YbFiber Laser Welding of a Maraging Steel, WELDING JOURNAL, v.93 (2014) 362-368.

9. AEROSPACE MATERIAL SPECIFICATIONS, AMS 6521C: Stee Sheet, Strip, and Plate, Maraging, 18.5Ni - 9.0Co - 4.9Mo - 0.65T - 0.10Al, Consumable Electrode Melted, Solution Heat Treated. USA, 1991

10. AMERICAN SOCIETY FOR TESTING AND MATERIALS, ASTM E8/ E8M-13: Standard Test Methods for Tension Testing of Metallic Materials. USA, 2013

11. SANTOS, D. R., Otimização dos parâmetros de tratamento térmico e soldagem do aco maraging 18Ni 300. 2001. $118 \mathrm{f}$ Dissertação (Mestrado em Engenharia Mecânica). Universidade Estadual Paulista "Julio de Mesquita Filho" - Faculdade de Engenharia de Guaratinguetá, Guaratinguetá, 2001.

12. SILVA, D. F., Caracterização Mecânica e Microestrutural do aço Maraging 300, soldado a plasma e submetidas a reparos. Dissertação apresentada à Faculdade de Engenharia do Campus de Guaratinguetá, Universidade Estadual Paulista, para a obtenção do título de Mestre em Engenharia Mecânica na área de Materiais, 2014.

13. SAKAI, P.R.; LIMA. M. S. F.; FANTON, L.; GOMES, C.V.; LOMBARDO, S.; ABDALLA, A.J., Comparison of Mechanical and Microstructural Characteristics in Maraging 300 Steel Welded by three different processes: LASER, PLASMA and TIG. Procedia Engineering, v.113 (2015) 291-297.

14. SOUZA NETO, F.; SIQUEIRA, R.H.M.; LIMA, M.S.F.; ABDALLA, A.J., Comparação das Propriedades Mecânicas em um Aço 4130 após Soldagem pelo Processo TIG e a Laser. Anais do $8^{\circ}$ Congresso Brasileiro de Engenharia de Fabricação, 2015, 7p.

15. BÖHLER. Maraging high strength steel V720 DE - 11.2007 - EM WS. Disponível em: http://www.bohler-edelstahl.com/. Acessado em: 30 de setembro de 2015 .

16. SAKAI, P.R.., Caracterização de juntas soldadas em paw e gtaw de chapas finas em aço maraging 300 submetidas a vários reparos. Tese apresentada à Faculdade de Engenharia do Campus de Guaratinguetá, Universidade Estadual Paulista, para a obtenção do título de Doutor em Engenharia Mecânica na área de Materiais,2015, 181p. 